Int J Obes (Lond). 2010 October ; 34(0 1): S47-S55. doi:10.1038/ijo.2010.184.

\title{
Adaptive thermogenesis in humans
}

\author{
Michael Rosenbaum and Rudolph L. Leibel \\ Columbia University, College of Physicians \& Surgeons, Departments of Pediatrics and Medicine, \\ Division of Molecular Genetics, New York, NY, 10032
}

\begin{abstract}
The increasing prevalence of obesity and its co-morbidities reflects the interaction of genes that favor the storage of excess calories as fat with an environment that provides ad libitum availability of calorically dense foods and encourages an increasingly sedentary lifestyle. While weight reduction is difficult in and of itself, anyone who has every lost weight will confirm that it is much harder to keep the weight off once it has been lost. The over $80 \%$ recidivism rate to pre-weight loss levels of body fatness after otherwise successful weight loss is due to the coordinate actions of metabolic, behavioral, neuroendocrine, and autonomic responses designed to maintain body energy stores (fat) at a CNS- defined "ideal". This "adaptive thermogenesis" creates the ideal situation for weight regain and is operant in both lean and obese individuals attempting to sustain reduced body weights. Much of this opposition to sustained weight loss is mediated by the adipocyte-derived hormone "leptin". The multiplicity of systems regulating energy stores and opposing the maintenance of a reduced body weight illustrate that body energy stores in general and obesity in particular are actively "defended" by interlocking bioenergetic and neurobiological physiologies. Important inferences can be drawn for therapeutic strategies by recognizing obesity as a disease in which the human body actively opposes the "cure" over long periods of time beyond the initial resolution of symptomatology.
\end{abstract}

\section{Keywords}

Obesity; Adaptive Thermogenesis; Thyroid; Autonomic; Weight Loss

\section{Introduction}

Western societies tend to regard obesity, and the inability of individuals to sustain weight loss, as largely self-imposed conditions which reflect a lack of "will power" related to lifestyle changes. Optimal levels of adiposity are often defined by cosmetic rather than medical considerations. However, genetic, epidemiological, and physiological studies indicate that body fatness/weight is regulated, and that the increasing prevalence of obesity in western societies reflects the interactions of genes favoring energy conservation and storage with an environment which enables access to food calories and a more sedentary lifestyle.

Throughout most of human evolution the tendency to store calories as fat would likely have conferred an advantage by enabling survival during periods of prolonged caloric restriction, as well as providing greater energy stores to nourish mother and fetus during and following pregnancy. Thus, it is likely that the human genome would be enriched for alleles of genes favoring the storage of calories as adipose tissue ${ }^{1}$. Our current environment enables the

Address correspondence to: Michael Rosenbaum, M.D. Division of Molecular Genetics, Russ Berrie Medical Science Pavilion, $6^{\text {th }}$ Floor, 1150 St. Nicholas Avenue, New York, NY 10032, Tel: 212-305-9949, Fax: 212-304-5210, mr475@ columbia.edu. 
consumption of large quantities of calorically dense foods and the maintenance of an increasingly sedentary lifestyle. Clearly not everyone has the same "genetic risk" for obesity and, regardless of any genetic proclivities, anyone will gain weight if they consume more calories than they expend. As illustrated by diet-induced obesity (DIO)-prone and DIOresistant mouse strains ${ }^{2}$, as well as humans ${ }^{3,4}$, there is a heritable variability in the degree of weight gain that different individuals will experience in an adipogenic environment. This variability reflects, in part, heritable influences on how much an individual participates in such an environment by increasing energy intake and/or decreasing energy expenditure, and their metabolic responsiveness to an increase in energy intake relative to expenditure ${ }^{5}$.

Any change in the amount of energy stored, predominantly as adipose tissue (over 100,000 $\mathrm{kcal}$ in a 70-kg man) but also as protein and glycogen, must reflect a difference between energy taken in as food and energy expended in various forms of metabolic and physical work (see below). If energy intake and output were not regulated by interlocking control mechanisms that work concordantly to maintain energy stores, then a very small persistent change in input relative to output would, over time, lead to substantial gain or loss of stored calories. Yet, the average U.S. adult gains only 500-1000 g of weight (approximately 2000$2500 \mathrm{kcal}$ of stored energy) per year (more pronounced in older individuals, AfricanAmericans, Native-Americans, and Hispanic-Americans) ${ }^{6}$, despite ingestion of approximately $900,000-1,000,000 \mathrm{kcal} / \mathrm{year}$. The remarkable constancy of body weight in this context, presumably without conscious constant calculation of how many calories are being consumed and/or expended by most individuals, suggests that energy intake and expenditure vary directly to maintain relatively stable energy stores ${ }^{7}$.

\section{Metabolic responses to attempts to sustain weight loss}

In long-term studies of weight-reduced children and adults, 80\%-90\% return to their previous weight percentiles ${ }^{8}$, while studies of those successful at sustained weight loss indicate that the maintenance of a reduced degree of body fatness will probably require a lifetime of meticulous attention to energy intake and expenditure 9,10 . The inability of most otherwise successfully weight-reduced individuals to sustain weight loss reflects the actions of potent and redundant metabolic, neuroendocrine, and autonomic systems (see below).

The responses of lean and obese individuals to experimental perturbations of body weight suggest that the magnitude of stored energy, particularly fat, is defended by central nervous system-mediated mechanisms that are similar, if not identical in lean and obese individuals. In both lean and obese individuals, there is potent "opposition" to the maintenance of reduced body weight that is achieved by coordinated regulation of energy intake and expenditure mediated by signals emanating from adipose, gastrointestinal, and endocrine tissues, and integrated by the liver and by central nervous system (see Table 1).

\section{Energy expenditure}

Maintenance of a $10 \%$ or greater reduction in body weight in lean or obese individuals is accompanied by an approximate $20 \%-25 \%$ decline in 24-hour energy expenditure. This decrease in weight maintenance calories is $10-15 \%$ below what is predicted solely on the basis of alterations in fat and lean mass ${ }^{11,12}$. Thus, a formerly obese individual will require $\sim 300-400$ fewer calories per day to maintain the same body weight and physical activity level as a never-obese individual of the same body weight and composition. Studies of individuals successful at sustaining weight loss indicate that reduced weight maintenance requires long-term lifestyle alterations ${ }^{9}$. The necessity for these long-term changes is consistent with the observation that the reduction in twenty four hour energy expenditure (TEE) persists in subjects who have sustained weight loss for extended periods of time (6 
months -7 years) in circumstances of enforced caloric restriction in the biosphere 2 project ${ }^{13}$, bariatric surgery ${ }^{14}$ and lifestyle modification ${ }^{15}$.

Twenty-four hour energy expenditure (TEE) is the sum of resting energy expenditure (REE; cardiorespiratory work and the work of maintaining transmembrane ion gradients at rest; approximately $60 \%$ of TEE), the thermic effect of feeding (TEF; the work of digestion; approximately $5-10 \%$ of TEE), and non-resting energy expenditure (NREE, energy expended in physical activity above resting; approximately 30-40\% of TEE). The effects of maintenance of reduced weight on each of these compartments of energy expenditure are distinctly different. There is no significant decline in TEF following weight loss ${ }^{11}$. Some studies ${ }^{16-18}$ report no change in REE following weight loss, while in others the maintenance of a reduced body weight is associated with modest reductions in REE accounting for about 10-15\% of the decline in TEE beyond that predicted on the basis of body composition changes $11,12,19$. The variability in study results probably reflects differences among studies in multiple factors including degree and duration of weight stability before and after weight loss as well as changes in subject fitness and time spent in physical activity following weight loss. Regardless of whether or not changes in REE account for 10-15\% of the changes in TEE following weight loss, NREE is clearly the compartment of energy expenditure that is most affected by changes in body weight 11,20 consistent with the importance of physical exercise in the successful maintenance of reduced weight 9,21 .

The pre-eminence of NREE - accounting for as much of $85-90 \%$ of the decline in TEE below predicted values in weight-reduced subjects 20,22 could be due to declines in the actual amount of physical activity performed. In rodents, maintenance of a reduced body weight is associated with an increase, rather than decrease, in the amount of time spent in physical activity ${ }^{23}$, probably reflecting food-seeking behavior. In-patient and out-patient studies of humans following weight loss have reported, respectively, no change or as much as a $30 \%$ increase in the amount of time that subjects spend moving each day, 11,18 supporting the view that skeletal muscle work efficiency is increased ${ }^{20}$ (as opposed to decreased amount of motion per se) following weight loss. Since these effects are most evident at low levels of work, i.e., those commensurate with activities of daily living, it is reasonable to infer that some of the opposition to reduced weight maintenance can be diminished by exercising at higher levels of power output 20,24 .

Studies of skeletal muscle chemomechanical efficiency (calories expended above resting per unit of power generated) in weight-reduced subjects indicate that maintenance of a reduced body weight is associated with an approximate $20 \%$ increase in skeletal muscle work efficiency at low levels of exercise, whether measured by bicycle ergometry or ${ }^{31} \mathrm{P}-\mathrm{NMR}$ muscle spectroscopy ${ }^{20}$. Ergometric studies measure whole body energy expenditure during stationary cycling. Energy efficiency is expressed as kcal consumed above REE per unit of power generated. Fuel utilization (fatty acid vs. glucose oxidation) is assessed by the respiratory exchange ratio (RER, ratio of $\mathrm{CO}_{2}$ produced to $\mathrm{O}_{2}$ consumed). In ${ }^{31} \mathrm{P}-\mathrm{NMR}$ spectroscopy, the ratio of inorganic phosphate $(\mathrm{Pi})$, which increases during exercise due to the hydrolysis of ATP, to phosphocreatine (PCr) which decreases during exercise to replenish ATP, during exercise, reflects the efficiency of muscle in generating a specific amount of power. In addition, the resting Pi reflects the relative fatty acid to glucose oxidative potential of muscle, and the phosphocreatine recovery constant ( $\mathrm{kPCr}$, a constant reflecting the exponential rate of $\mathrm{PCr}$ resynthesis following exercise as well the maximal rate of oxygen consumption by muscle) reflects the muscle glycolytic potential ${ }^{20,25.31} \mathrm{P}$ NMR spectroscopy can also be used to examine the in vivo ATP cost of single muscle contraction by measuring the $\mathrm{PCr}$ depletion rate following muscle stimulation in an ischemic limb (no PCr repletion until blood flow is restored) ${ }^{26}$. Both of these methods demonstrate 
that the maintenance of a $10 \%$ reduced body weight is associated with an approximate $20 \%$ increase in skeletal muscle chemomechanical efficiency and an approximate $18 \%$ relative increase in the fractional use of free fatty acids as fuel during low level exercise ${ }^{20,27}$ (see Table 2). These results are consistent with studies of vastus lateralis muscle biopsies in which the ratio of glycolytic (phosphofructokinase, PFK) to oxidative (cytochrome oxidase) enzyme activities is significantly decreased following weight loss. The changes in these enzyme ratios are sufficient to account in statistical analyses for a significant fraction of the increased efficiency $\left(\mathrm{R}^{2}=0.57, \mathrm{p}<0.001\right)$ and free fatty acid oxidation $\left(\mathrm{R}^{2}=0.31, \mathrm{p}<0.01\right)$ that occurs during low level-exercise in weight-reduced subjects ${ }^{27}$.

\section{Neuroendocrine Function}

The neuroendocrine changes associated with the maintenance of a reduced body weight include increased activity of the hypothalamic-pituitary-adrenal (HPA) axis and decreased activity of the hypothalamic-pituitary-thyroid (HPT) and hypothalamic-pituitary-gonadal (HPG) axes. The hypothalamic pro-opiomelanocortin (POMC)-melanocortin-melanocortin 4 receptor (MC4R) pathway, by virtue of its constituent neuronal outflow tracts to the ANS, neuroendocrine axes, and cortical tracts subserving food intake, may provide a central nexus for the sum of the integrated effects on energy expenditure and intake that are seen following weight loss $1,28,29$.

The importance of the HPA axis in regulating body fat stores is illustrated by the effects of adrenalectomy on genetically obese rodents. The leptin-deficient or leptin-resistant mouse is hyperphagic, hypometabolic (much like the weight-reduced human as discussed below), hypercortisolemic (unlike leptin-deficient and resistant humans), and severely obese. These phenotypes are abolished by chemical or surgical adrenalectomy ${ }^{30}$. Hypercortisolemia results in loss of lean body mass and increases the partitioning of stored calories to fat ${ }^{1}$.

Studies of the HPA axis in which human subjects were assessed following variable weight loss regimens and lengths of time maintaining a reduced weight have found increases ${ }^{31}$, decreases ${ }^{32}$, and no change ${ }^{33}$ in indices of cortisol production following weight loss. Discrepancies among studies may reflect differences in subject populations regarding exercise, gender, age, or weight loss regimens, as well as the degree of weight stability at the time of study.

Thyroid hormone increases energy expenditure by increasing heart rate, blood pressure, muscle ATP consumption (largely by stimulating production of muscle ATPase). The thyroid hormone deficient patient is hypotensive, bradycardic, and lethargic and tends to gain weight while the hyperthyroid patient is hypertensive and tachycardic and tends to lose weight ${ }^{34,35}$. Both weight loss and the maintenance of a reduced body weight are associated with small but statistically significant decreases in circulating concentrations of triiodothyronine (T3) and increases in the circulating concentrations of its bioinactive enantiomer reverse T3 (rT3), suggesting that weight loss results in increased peripheral conversion of thyroxine (T4) to rT3 ${ }^{36}$. Thyroid releasing hormone (TRH)-stimulated pituitary thyroid stimulating hormone (TSH) release is not diminished during caloric restriction ${ }^{37}$ or after weight loss ${ }^{38}$ in humans. The lack of increase in TSH with weight loss, despite the decrease in circulating concentrations of T3, indicates that hypothalamic TRH release is decreased following weight loss. Caloric restriction and maintenance of a reduced body weight are associated with decreased circulating leptin concentrations (see below) ${ }^{39}$. Low ambient leptin, in turn, reduces POMC production in hypothalamic neurons. Decreased hypothalmic alpha-MSH (a-MSH), a proteolytic product of POMC, results in decreased activity of hypothalamic pro-thyroid releasing hormone (pro-TRH) neurons in rats ${ }^{40}$, thus providing a possible mechanism for the decrease in HPT axis activity following 
weight loss and the restoration of circulating concentrations of bioactive thyroid hormones following leptin replacement ${ }^{41}$.

\section{Autonomic Nervous System Function}

The autonomic nervous system (both parasympathetic and sympathetic) includes major outflow tracts linking afferent biochemical signals regarding energy stores and efferent tracts regulating energy expenditure. Increased parasympathetic nervous system activity slows heart rate and decreases resting energy expenditure. The sympathetic branch of the autonomic nervous system modulates feeding behavior, directly increases heart rate, and acts directly on the thyroid gland to increase the rate of secretion of thyroid hormone 42,43 . Sympathetic denervation of the arm in humans with palmar hyperhidrosis improves skeletal muscle work efficiency ${ }^{44}$ in arm muscles, and chemical sympathectomy attenuates leptinmediated increases in energy expenditure in rats ${ }^{45}$. Daily urinary norepinephrine excretion accounts for a significant proportion of the variance in energy expenditure and its subcomponents in weight stable subjects ${ }^{36}$.

The maintenance of a reduced body weight is associated with significant declines in SNS tone (by analysis of heart rate following sequential parasympathetic and sympathetic blockade or 24-hour urinary catecholamine excretion) and increases in PNS tone 36, 43, 46 . Changes in ANS tone associated with weight loss, in particular the decline in sympathetic nervous system tone, may account for a significant fraction of the hypometabolic state through direct effects on skeletal muscle, and/or indirectly via effects on circulating concentrations of thyroid hormones $36,47,48$. Thus, weight-loss mediated changes in autonomic nervous system activity may constitute a link between weight-loss associated changes in energy and neuroendocrine homeostasis.

\section{Brown Adipose Tissue}

Brown adipose tissue (BAT) allows the uncoupling of mitochondrial substrate oxidation from ATP production thereby releasing the energy of fatty acid oxidation as heat ${ }^{49}$. This is achieved via a 32kd "uncoupling protein" (UCP1) which is present in BAT, but not in white adipose tissue (WAT). BAT has a rich sympathetic nerve and vascular supply and, in the presence of cold, weight gain, and/or sympathetic nervous stimulation in rodents or exogenous or endogenous hypercatecholaminemia in humans, BAT activity increases resulting in heat generation ${ }^{50,51}$ The activation of BAT is dependent upon integration of input from the sympathetic nervous system activation of adrenoreceptors (predominantly $\left.\beta_{3}\right)^{52}$, with activation of at least one of the thyroid hormone receptors (TR) subtypes (TRa or TR $\beta)^{53}$. The leptin-sensitive declines in sympathetic nervous system activity and circulating concentrations of bioactive thyroid hormones following weight loss that are described above constitute a mechanism by which reduced obligatory and/or facultative thermogenesis by BAT could contribute to adaptive thermogenesis in humans. As little as $25 \mathrm{gm}$ of BAT going from a maximally active to a minimally active state following weight loss would be more than sufficient to account for the magnitude of decline in REE in weight-reduced subjects that occurs beyond that predicted solely on the basis of weight and body composition changes ${ }^{54}$. Therefore, it is possible that a significant fraction of the unexplained variance in resting energy expenditure or in changes in resting energy expenditure following weight loss is attributable to changes in the activity or brown adipose tissue (BAT) ${ }^{55}$.

However, while BAT is a major contributor to adaptive thermogenesis in small mammals ${ }^{56}$, its role in thermogenesis in adult humans remains unclear. In rodents, BAT contributes to both obligatory thermogenesis (the heat produced to maintain body temperature at rest) and facultative thermogenesis (the heat produced to maintain body temperature at ambient 
temperatures below thermoneutrality) ${ }^{53}$. The cold intolerance of hypothyroid rodents reflects declines in both obligatory and facultative thermogenesis by BAT ${ }^{53}$. BAT is easily detected in rodents and clearly plays a role in non-shivering thermogenesis in human neonates.

Previous studies showed a lack of a significant presence of BAT in humans except under extreme conditions of hypercatecholaminemia ${ }^{57}$ and, until recently, no studies have been carried out quantifying the contribution of BAT to total adaptive thermogenesis in humans. Recent advances in positive emission tomography (PET) scanning technology have allowed detailed imaging of BAT using uptake of $2-\left[{ }^{18}\right.$ F]fluoro-2-desoxy-glucose (FDG) and a hybrid scanner. FDG uptake has been shown to correspond to the neck, supraclavicular, mediastinal, paraspinal, paravertebral and renal areas known to contain BAT in humans $58,59,60$ and FDG uptake in these areas (www.med.harvard.edu/JPNM/chetan/ normals/brown_fat/case.html) is inhibited by $\beta$-adrenergic blockade with propranolol ${ }^{61-63}$. In a recent series of papers $54,64,65$, several groups demonstrated the ability to detect BAT in healthy human beings with varying results as to whether thermal stimuli are necessary to detect it. In a retrospective study of $\left[{ }^{18} \mathrm{~F}\right] \mathrm{FDG}$ (dose not specified) PET scans, Cypress et al ${ }^{54}$ detected BAT in $7.5 \%$ of women and $3.1 \%$ of men studied under thermoneutral conditions. Lichtenbelt et al ${ }^{64}$ found that BAT was detected in 23/24 subjects after cold exposure $\left(16^{\circ} \mathrm{C}\right.$ for 2 hours) but was not detected in 3 of these subjects who were also studied under thermoneutral conditions $\left(\left[{ }^{18} \mathrm{~F}\right] \mathrm{FDG}\right.$ dose of $\left.74 \mathrm{MBq}\right)$. Finally, Virtanen et al ${ }^{65}$ reported that BAT was detected in $5 / 5$ adult subjects under both thermoneutral and post-cold exposure $\left(19^{\circ} \mathrm{C}\right.$ for 2 hours) conditions using a higher dose $(185 \mathrm{MBq})$ of $\left[{ }^{18} \mathrm{~F}\right] \mathrm{FDG}$.

The anatomic identification of BAT in humans using FDG does not necessarily reflect actual thermogenic activity of BAT, and the question remains as to whether BAT actually participates in resting thermogenesis, diet-induced thermogenesis, or adaptive thermogenesis following weight loss or gain in humans. Increased glucose uptake by BAT is considered to reflect increased metabolic activity and thermogenesis $56,66,67$. This is the basis for the use of the FDG PET technique in localization of tumors and for the analysis of brain areas involved in different cognitive activities as well as for examining myocardial metabolic activity $^{56}$. Thus, the FDG uptake seen in brown adipose tissue in adult man implies the existence of thermogenically active tissue in adult man. The magnitude of glucose uptake by BAT in FDG PET studies of subjects fasted and at rest, compared to other tissues, also suggests that BAT may play a significant role in glucose disposal in low activity states (i.e., the state in which we spend at least $1 / 3$ of our lives). Assuming that reduced BAT activation following weight loss is a significant factor in adaptive thermogenesis, this effect is more likely to be evident in obligatory than facultative thermogenesis. In this environment we spend almost all of our time in thermoneutral conditions reducing the need for facultative thermogenesis and possibly contributing to the increasing prevalence of obesity 68,69 . Further studies of the role of BAT in human thermogenesis outside of the neonatal period are clearly indicated.

\section{Metabolic responses to attempts to sustain weight gain}

The metabolic changes that occur in subjects during maintenance of an elevated body weight following overfeeding involve many of the same systems but are not, in fact, mirror images of the changes following weight loss. In a manner complementary to that seen following weight loss, the maintenance of an elevated body weight is associated with significant increases in circulating concentrations of T3 and T4, SNS tone, TEE, NREE, and, of course, circulating leptin concentrations and a decreases in PNS tone and skeletal muscle work efficiency. However, there is no demonstrable effect of the maintenance of an elevated body weight on circulating concentrations of TSH, and there is a much more marked effect of 
elevated weight maintenance on TEF and less of an effect on REE than is seen following weight loss $11,36,70$.

Unlike the metabolic opposition to sustaining a reduced body weight, which persists long after weight reduction in mice ${ }^{71}$ and humans ${ }^{72}$, the increased energy expenditure noted during short-term overfeeding in mice seems to be short-lived. Rodents with diet-induced obesity demonstrate increased energy expenditure ${ }^{73}$ and increased SNS tone ${ }^{74}$ during the first 3-4 weeks of overfeeding. However, after a few months on a high fat diet, these changes are no longer evident 74,75 , indicating that resistance to sustained increased adiposity is less sustained than resistance to decreased adiposity ${ }^{69}$. The steadily increasing prevalence of obesity in humans also suggests that body fatness is facilitated more vigorously than body thinness. In addition to the lack of physiological persistence of strong metabolic opposition to weight gain, any "defense" against further weight gain is stretched to the limit by this lifestyle, while opposition to sustaining weight loss remains potent and viable ${ }^{76}$.

\section{Energy Intake}

As noted above, the long-term constancy of body weight suggests that energy intake and expenditure vary coordinately to maintain relatively stable energy stores. This "coupling" which reduces caloric intake in response to decreased energy expenditure is disrupted during and following weight loss ${ }^{7}$. During dynamic weight loss, human beings and rodents are both hungrier (willing to eat more often) and less satiated (willing to eat more per meal) ${ }^{77}$. Even during maintenance of a reduced weight, satiety remains diminished despite the decline in energy expenditure ${ }^{78}$. The simultaneous declines in both energy expenditure and satiety following weight loss conspire to create the optimal biological circumstance for weight regain.

\section{Leptin in Energy Homeostasis}

A critical mediator of these reciprocal changes in energy intake and expenditure is the hormone leptin. Leptin is an adipocyte derived molecule that circulates in weight-stable individuals in direct proportion to fat mass ${ }^{79}$. The hyperphagic, hypometabolic phenotype of weight-reduced humans is similar to that of leptin-deficient or -unresponsive humans and rodents ${ }^{80}$. Circulating leptin concentrations are inversely correlated with hunger ratings in humans during weight loss, independent of the amount of weight or body fat lost ${ }^{81}$. Leptin administration reverses the hyperphagia associated with leptin deficiency in leptin-deficient mice and humans 82,83 , and acts synergistically with sibutramine to reduce food intake in rodents ${ }^{84}$. Leptin suppresses food intake by promoting the production of anorexigenic neuropeptides (processed products of POMC) and reducing the expression of orexigens such as neuropeptide Y (NPY), agouti-related peptide (AgRP), and melanin concentrating hormone $(\mathrm{MCH})$. Thus, decreased circulating leptin concentrations as a result of reduced fat mass has the net effect of stimulating food intake ${ }^{1}$.

The hypothalamic POMC-melanocortin-MC4R pathway is highly sensitive to circulating leptin concentrations and POMC expression is decreased in low-leptin states 29,85 . Briefly, POMC is cleaved to alpha-melanocyte stimulating hormone (a-MSH) and beta-endorphin $(\beta$-EP) as well as other bioactive molecules. As discussed previously, $a-\mathrm{MSH}$ stimulates release of hypothalamic pro-TRH. $\beta$-EP inhibits the release of hypothalamic corticotropin releasing factor (CRF). Therefore, reduced ambient leptin induced by weight loss, should be associated with decreased HPT and increased HPA axis activity. Mice overexpressing the melanocortin 4 receptor (MC4R) antagonists agouti signaling protein (ASP) or agoutirelated peptide (AgRP) ${ }^{86}$ - as well as rodents and humans with hypomorphic mutations in MC4R ${ }^{87}$, disruptions of POMC gene expression ${ }^{88,89}$ or of proproneuropeptide (e.g., 
POMC, pro-ACTH, pro-TRH) processing by prohormone convertases 90,91 - are obese. The importance of leptin in mediating these effects is reflected in the observation that fasting in rodents causes hypoleptinemia that is associated with increased arcuate and brainstem NPY and AgRP mRNA expression and decreased POMC mRNA in lean animals, but not in leptin-receptor deficient animals ${ }^{92}$.

Administration of leptin to leptin-deficient rodents and humans in doses that restore circulating leptin concentrations to their physiological range increases energy expenditure ${ }^{93}$, decreases energy intake, increases sympathetic nervous system activity ${ }^{94}$, and normalizes hypothalamic-pituitary-adrenal, thyroid, and gonadal function ${ }^{1,29,82}$. Yet, in humans (lean or obese) and rodents who are not leptin-deficient, induction of weight loss requires doses of leptin that produce plasma leptin concentrations over 10 times normal ${ }^{95,96}$. Recent studies of the short-term administration of leptin to weight-reduced lean and obese subjects suggest that restoration of circulating concentrations of leptin to levels present prior to weight loss reverses the decreased energy expenditure, and its associated declines in thyroid hormone and SNS activity and increase in skeletal muscle work efficiency, and increased energy intake, measured behaviorally and by functional magnetic resonance imaging of neuronal responses to food, that characterize the weightreduced state ${ }^{78,82,97}$. In this sense, the weight-reduced state may be perceived by CNS components relevant to energy homeostasis as a state of relative leptin deficiency.

Pharmacotherapy activating the leptin-signaling pathway may help weight-reduced individuals to sustain their weight loss ${ }^{98}$.

\section{Summary}

Attempts to sustain weight loss invoke adaptive responses involving the coordinate actions of metabolic, neuroendocrine, autonomic, and behavioral changes that "oppose" the maintenance of a reduced bodyweight. This phenotype is distinct from that opposing dynamic weight loss per se. The multiplicity of systems regulating energy stores and opposing the maintenance of a reduced body weight illustrate that body energy stores in general and fat stores in particular are actively "defended" by interlocking bioenergetic and neurobiological physiologies. Important inferences can be drawn for therapeutic strategies by recognizing obesity as a state in which the human body actively opposes the "cure" over long periods of time beyond the initial resolution of symptomatology.

\section{References}

1. Leibel, R.; Chua, S.; Rosenbaum, M. Chapter 157. Obesity. In: Scriver, C.; Beaudet, A.; Sly, W.; Valle, D., editors. The metabolic and molecular bases of inherited disease. 8. Vol. III. New York: McGraw-Hill; 2001. p. 3965-4028.

2. West DB, Boozer CN, Moody DL, Atkinson RL. Dietary obesity in nine inbred mouse strains. Am J Physiol. 1992; 262:R1025-R32. [PubMed: 1621856]

3. Bouchard C, Tremblay A. Genetic influences on the response of body fat and fat distribution to positive and negative energy balances in human identical twins. J Nutr. 1997; 127:943S-47S. [PubMed: 9164270]

4. Bouchard C, Tremblay A, Despres JP, Nadeau A, Lupien PJ, Theriault G, et al. The response to long-term overfeeding in identical twins. N Engl J Med. 1990; 322:1477-82. [PubMed: 2336074]

5. Rosenbaum M. Epidemiology of pediatric obesity. Ped Annals. 2007; 36:89-95.

6. Lewis C, Jacobs D, McCreath H, Kiefe C, Schreiner P, Smith D, et al. Weight gain continues in the 1990s: 10-year trends in weight and overweight from the CARDIA study. Coronary Artery Risk development in Young Adults. Am J Epidemiol. 2000; 151:1172-81. [PubMed: 10905529]

7. Moore M. Interactions between physical activity and diet in the regulation of body weight. Proc Nutr Soc. 2000; 59:193-98. [PubMed: 10946787] 
8. McGuire M, Wing R, Klem M, Hill J. Behavioral strategies of individuals who have maintained long-term weight losses. Obes Res. 1999; 7:334-41. [PubMed: 10440589]

9. Wing R, Hill J. Successful weight loss maintenance. Annu Rev Nutr. 2001; 21:323-41. [PubMed: 11375440]

10. Klem M, Wing R, Lang W, McGuire M, Hill J. Does weight loss maintenance become easier over time. Obes Res. 2000; 8:438-44. [PubMed: 11011910]

11. Leibel R, Rosenbaum M, Hirsch J. Changes in energy expenditure resulting from altered body weight. N Eng J Med. 1995; 332:621-28.

12. Weigle D, Sande K, Iverius P, Monsen E, Brunzell J. Weight loss leads to a marked decrease in nonresting energy expenditure in ambulatory human subjects. Metabolism. 1988; 37:930-36. [PubMed: 3173112]

13. Weyer C, Walford R, Harper I, Milner M, MacCallum T, Tataranni P, et al. Energy metabolism after 2 y of energy restriction: the biosphere 2 experiment. Am J Clin Nutr. 2000; 72:946-53. [PubMed: 11010936]

14. Gemert, Wv; Westerterp, K.; Acker, Bv; Wagenmakers, A.; Halliday, D.; Greve, J., et al. Energy, substrate and protein metabolism in morbid obesity before, during and after massive weight loss. Int J Obes. 2000; 24:711-18.

15. Leibel R, Hirsch J. Diminished energy requirements in reduced-obese patients. Metabolism. 1984; 33:164-70. [PubMed: 6694559]

16. dePeuter R, Withers R, Brinkman M, Tomas F, Clark D. No differences in rates of energy expenditure between post-obese women and their matched, lean controls. Int J Obes. 1992; 16:801-08.

17. Amatruda J, Statt M, Welle S. Total and resting energy expenditure in obese women reduced to ideal body weight. J Clin Invest. 1993; 92:1236-42. [PubMed: 8376583]

18. Weinsier R, Hunter G, Zuckerman P, Redden D, Darnell B, Larson D, et al. Energy expenditure and free-living physical activity in black and white women: comparison and after weight loss. Am J Clin Nutr. 2000; 71:1138-46. [PubMed: 10799376]

19. Astrup A, Gotzsche P, Werken Kvd, Ranneries C, Toubro S, Raben A, et al. Meta-analysis of resting metabolic rate in formerly obese subjects. Am J Clin Nutr. 1999; 69:1117-22. [PubMed: 10357728]

20. Rosenbaum M, Vandenborne K, Goldsmith R, Simoneau J, Heymsfield S, Joanisse D, et al. Effects of experimental weight perturbation on skeletal muscle work efficiency in human subjects. Amer J Physiol. 2003; 285:R183-92.

21. Klem M, Wing R, McGuire M, Seagle H, Hill J. A descriptive study of individuals successful at long term maintenance of substantial weight loss. Am J Clin Nutr. 1998; 66:239-46. [PubMed: 9250100]

22. Newcomer B, Larson-Meyer D, Hunter G, Weinsier R. Skeletal muscle metabolism in overweight and post-overweight women: an isometric exercise study using (31)P magnetic resonance spectroscopy. Int J Obes. 2001; 25:1309-15.

23. Pirke K, Briicjs A, Wilckens T, Marquard R, Schweiger U. Starvation induced hyperactivity in the rat: the role of endocrine and neurotransmitter changes. Neurosci Biobehav Rev. 1993; 17:287-94. [PubMed: 7903806]

24. Freyschuss U, Melcher A. Exercise energy expenditure in extreme obewsity: influence of ergometry type and weight loss. Scand J Clin Lab Invest. 1978; 38:753-59. [PubMed: 741204]

25. Walter G, Vandenborne K, McCully K, Leigh J. Noninvasive measurement of PCr recovery kinetics in single human muscles. Am J Physiol. 1997; 268:C869-76. [PubMed: 7733235]

26. Blei M, Conley K, Kushmerick M. Separate measures of ATP utilization and recovery in human skeletal muscle. J Physiol (Lond). 1993; 465:203-22. [PubMed: 8024651]

27. Goldsmith R, Joanisse D, Gallagher D, Pavlovich K, Shamoon E, Leibel R, et al. Effects of experimental weight perturbation on skeletal muscle work efficiency, fuel utilization, and biochemistry in human subjects. Am J Physiol. 2009 In Press.

28. Schwartz M, Woods S, Porte D, Seeley R, Baskin D. Central nervous system control of food intake. Nature. 2000; 404:661-70. [PubMed: 10766253] 
29. Wardlaw S. Clinical review 127: Obesity as a neuroendocrine disease: lessons to be learned from proopiomelanocortin and melanocortin receptor mutations in mice and men. J Clin Endocrinol Metab. 2001; 86:1442-6. [PubMed: 11297566]

30. Shimomura Y, Bray GA, Lee M. Adrenalectomy and steroid treatment in obese (ob/ob) and diabetic (db/db) mice. Horm Metab Res. 1987; 19:295-99. [PubMed: 2957297]

31. Kennedy S, Brown G, McVrey G, Garfinkel P. Pineal and adrenal function before and after refeeding in anorexia nervosa. Biol Psych. 1991; 30:216-24.

32. Guldstrand M, Ahren B, Wredling R, Backman L, Linus P, Adamson U. Alteration of the counterregulatory responses to insulin-induced hypoglycemia and of cognitive function after massive weight reduction in severely obese subjects. Metabolism. 2003; 52:900-07. [PubMed: 12870168]

33. Yanovski J, Yanovski S, Gold P, Chorousos G. Differences in corticotropin-releasing hormonestimulated adrenocorticotropin and cortisol before and after weight loss. J Clin Endocrinol Metab. 1997; 82:1874-78. [PubMed: 9177399]

34. Danforth E, Burger A. The role of thyroid hormones in the control of energy expenditure. Clin Endocrinol Metab. 1984; 13:581-96. [PubMed: 6391756]

35. al-Adsani H, Hoffer L, Silva J. Resting energy expenditure is sensitive to small dose changes in patients on chronic thyroid hormone replacement. J Clin Endocrinol Metab. 1997; 82:1118-25. [PubMed: 9100583]

36. Rosenbaum M, Hirsch J, Murphy E, Leibel R. The effects of changes in body weight on carbohydrate metabolism, catecholamine excretion, and thyroid function. Amer J Clin Nutr. 2000; 71:1421-32. [PubMed: 10837281]

37. Goodwin G, Fairburn C, Keenan J, Cowen P. The effects of dieting and weight loss upon the stimulation of thyrotropin (TSH) by thyrotropin-releasing hormone (TRH) and suppression of cortisol secretion by dexamethasone in men and women. J Affect Dis. 1988; 14:137-44. [PubMed: 2966827]

38. Guzzaloni G, Grugni G, Moro D, Calo G, Tonelli E, Ardizzi A, et al. Thyroid-stimulating hormone and prolactin responses to thyrotropin-releasing hormone in juvenile obesity before and after hypocaloric diet. J Encodrinol Invest. 1995; 18:621-29.

39. Rosenbaum M, Nicolson M, Hirsch J, Murphy E, Chu F, Leibel R. Effects of weight change on plasma leptin concentrations and energy expenditure. J Clin Endocrinol Metab. 1997; 82:3647-54. [PubMed: 9360521]

40. Fekete C, Legradi G, Mihaly E, Huang Q, Tatro J, Rand W, et al. alpha-Melanocyte-stimulating hormone is contained in nerve terminals innervating thyrotropin-releasing hormone-synthesizing neurons in the hypothalamic paraventricular nucleus and prevents fasting-induced suppression of prothyrotropin-releasing hormone gene expression. J Neurosci. 2000; 20:1550-58. [PubMed: 10662844]

41. Harris M, Aschkenasi C, Elias C, Chandrankunnel A, Nillni E, Bjorbaek C, et al. Transcriptional regulation of the thyrotropin-releasing hormone gene by leptin and melanocortin signaling. J Clin Invest. 2001; 107:111-20. [PubMed: 11134186]

42. Lang C, Rayos G, Chomsky D, Wood A, Wilson J. Effect of sympathoinhibition on exercise performance in patients with heart failure. Circulation. 1997; 96:238-45. [PubMed: 9236440]

43. Aronne L, Mackintosh R, Rosenbaum M, Leibel R, Hirsch J. Autonomic nervous system activity in weight gain and weight loss. Am J Physiol. 1995; 38:R222-25.

44. Kardos A, Taylor D, Thompson C, Styles P, Hands L, Collin J, et al. Sympathetic denervation of the upper limb improves forearm exercise performance and skeletal muscle bioenergetics.

Circulation. 2000; 13:2716-20. [PubMed: 10851209]

45. Dobbins R, Szczepaniak L, Zhang W, McGarry J. Chemical sympathectomy alters regulation of body weight during prolonged ICV leptin infusion. Am J Physiol. 2003; 284:E778-87.

46. Aronne L, Mackintosh R, Rosenbaum M, Leibel R, Hirsch J. Cardiac autonomic nervous system activity in obese and never-obese young men. Obes Res. 1997; 5:354-59. [PubMed: 9285844]

47. Kim M, Small C, Stanley S, Morgan D, Seal L, Kong W, et al. The central melanocortin system affects the hypothalamo-pituitary thyroid axis and may mediate the effect of leptin. J Clin Invest. 2000; 105:1005-11. [PubMed: 10749579] 
48. Flier J, Harris M, Hollenberg A. Leptin, nutrition, and the thyroid: the why, the wherefore, and the wiring. J Clin Invest. 2000; 105:859-61. [PubMed: 10749565]

49. Cannon B, Nedergaard J. Brown adipose tissue: function and physiological significance. Physiol Rev. 2004; 84:277-359. [PubMed: 14715917]

50. Trayhurn, P.; Nicholls, D., editors. Brown Adipose Tissue. Baltimore, MD: Edward Arnold; 1986. p. 117-23.

51. Leibel, R.; Berry, E.; Hirsch, J. In vivo evidence for catechol-responsive brown adipose tissue in obese patients. Proceedings Fifth International Congress on Obesity; Jerusalem, Israel. 1987;

52. Chemogubova E, Hurchinson D, Nedergaard J, Bengtsson T. Alpha1- and beta1-adrenoceptor signaling fully compensates for beta3-adrenoceptor deficiency in brown adipocyte norepinephrinestimulated glucose uptake. Endocrinology. 2005; 146:2271-84. [PubMed: 15665039]

53. Alkemade A. Central and peripheral effects of thyroid hormone signalling in the control of energy metabolism. J Neuroendocrinol. 2010; 22:56-63. [PubMed: 19912477]

54. Cypress A, Lehman S, Williams G, Tal I, Rodman D, Goldfine A, et al. Identification and importance of brown adipose tissue in adult humans. N Eng J Med. 2009; 360:1509-17.

55. Seale P, Lazar M. Brown fat in humans: turning up the heat on obesity. Diabetes. 2009; 68:148284. [PubMed: 19564460]

56. Nedergaard, J.; Connolly, E.; Cannon, B. Brown adipose tissue in the mammalian neonate. In: Trayhurn, P.; Nicholls, D., editors. Brown Adipose Tissue. Baltimore, MD: Edward Arnold; 1986. p. 152-213.

57. Astrup A, Bulow J, Madsen J, Christensen N. Contribution of BAT and skeletal muscle to thermogenesis induced by ephedrine in man. Am J Physiol. 1985; 248:E507-15. [PubMed: 3922230]

58. Nedergard J, Bengtsson T, Cannon B. Unexpected evidence for active brown adipose tissue in adult humans. Am J Physiol. 2007; 293:E444-52.

59. Truong M, Erasmus J, Munden R, Marom E, Sabloff B, Gladish G, et al. Focal FDG uptake in mediastinal brown fat mimicking malignancy: a potential pitfall resolved on PET/CT. Am J Roentgenol. 2004; 183:1127-32. [PubMed: 15385319]

60. Chib C, Katsuragi I, Simada T, Adachi I, Satoh Y, Noguchi H, et al. Evaluation of human brown adipose tissue using positron emission tomography, computerised tomography and histochemical studies in association with body mass index, visceral fat accumulation and insulin resistance (Abstract). Obes Rev. 2006; 7:87.

61. Jacobsson H, Bruzelius M, Larsson S. Reduction of FDG uptake in brown adipose tissue by propranolol. Eur J Nucl Mol Imaging. 2005; 32:1130.

62. Tatsumi M, Engles J, Ishimori T, Nicely O, Cohade C, Wahl R. Intense (18)F-FDG uptake in brown fat can be reduced pharmacologically. J Nucl Med. 2004; 45:1189-93. [PubMed: 15235065]

63. Soderlund V, Larsson S, Jacobsson H. Reduction of FGD uptake in brown adipose tissue in clinical patients by a single dose of propranolol. Eur J Nucl Med Mol Imaging. 2007; 45:1018-22. [PubMed: 17225118]

64. Lichtenbelt W, Vanjommeng J, Smulders N, Drossaerts J, Kemerink G, Bouvy N, et al. Coldactivated brown adipose tissue in healthy men. N Eng J Med. 2009; 360:1500-08.

65. Virtanen K, Lidell M, Orava J, Jeglind M, Westergren R, Niemi T, et al. Functional brown adipose tissue in healthy adults. N Eng J Med. 2009; 360:1518-25.

66. Chernogubova E, Cannon B, Bengtsson T. Norepinephrine increases glucose transport in brown adipocytes via 3-adrenoceptors through a cAMP, PKA and PI3-kinase-dependent pathway stimulating conventional and novel PKCs. Endocrinol. 2004; 145:269-80.

67. Marette A, Bukowiecki L. Noradrenaline stimulates glucose transport in rat brown adipocytes by activating thermogenesis. Evidence that fatty acid activation of mitochondrial respiration enhances glucose transport. Biochem J. 1991; 277:119-24. [PubMed: 1713031]

68. Elobeid M, Allison D. Putative environmental-endocrine disruptors and obesity: a review. Curr Opin Endocrinol Diabetes Obes. 2008; 15:403-08. [PubMed: 18769210]

69. Schwartz M, Woods S, Seeley R, Barsh G, Baskin D, Leibel R. Is the energy homeostasis system inherently biased toward weight gain? Diabetes. 2003; 52:232-38. [PubMed: 12540591] 
70. Tremblay A, Despres J, Theriault G, Fournier G, Bouchard C. Overfeeding and energy expenditure in humans. Am J Clin Nutr. 1992; 56:857-62. [PubMed: 1415004]

71. Dulloo A, Girardier L. 24 hour energy expenditure several months after weight loss in the underfed rat: evidence for a chronic decrease in whole-body metabolic efficiency. Int J Obes. 1993; 17:11523.

72. Rosenbaum M, Hirsch J, Gallagher D, Leibel R. Long-term persistence of adaptive thermogenesis in subjects who have maintained a reduced body weight. Amer J Clin Nutr. 2008; 88:906-12. [PubMed: 18842775]

73. Rothwell N, Stock M. Energy expenditure of cafeteria-fed rats determined from measurements of energy balance and indirect calorimetry. J Physiol London. 1982; 328:371-77. [PubMed: 7131317]

74. Levin BE, Triscari J, Sullivan AC. Altered sympathetic activity during development of dietinduced obesity in rat. Am J Physiol. 1983; 244:R347-R55. [PubMed: 6131610]

75. Corbett SW, Stern JS, Keesey RE. Energy expenditure in rats with diet-induced obesity. Am J Clin Nutr. 1986; 44:173-80. [PubMed: 3728354]

76. Murgatroyd P, Goldberg G, Leahy F, Prentice A. Effects of inactivity and diet composition on human energy balance. Int J Obes. 1999; 23:1269-75.

77. Doucet E, Cameron J. Appetite control after weight loss: what is the role of bloodborne peptides? Amer J Physiol Nutr Metab. 2007; 32:523-32.

78. Kissileff H, Thornton M, Torres M, Pavlovich K, Leibel R, Rosenbaum M. Maintenance of reduced body weight in humans is associated with leptin-reversible declines in satiation. 2010 (submitted).

79. Rosenbaum M, Nicolson M, Hirsch J, Heymsfield S, Gallagher D, Chu F, et al. Effects of gender, body composition, and menopause on plasma concentrations of leptin. J Clin Endocrinol Metab. 1996; 81:3424-27. [PubMed: 8784109]

80. Leibel R. The role of leptin in the control of body weight. Nutr Rev. 2002; 60:S15-19. [PubMed: 12403079]

81. Heini A, Lara-Castro C, Kirk K, Considine R, Caro J, Weinsier R. Association of leptin and hunger-satiety ratings in obese women. Int J Obes. 1998; 22:1084-87.

82. Farooqi I, Jebb S, Langmack G, Lawrence E, Cheetham C, Prentice A, et al. Effects of recombinant leptin therapy in a child with congenital leptin deficiency. N Eng J Med. 1999; 341:879-84.

83. Campfield LA, Smith FJ, Guisez Y, Devos R, Burn P. Recombinant mouse OB protein: evidence for a peripheral signal linking adiposity and central neural networks. Science. 1995; 269:546-49. [PubMed: 7624778]

84. Boozer C, Love R, Cha M, Leibel R, Aronne L. Synergy of leptin and sibutramine in treatment of diet-induced obesity in rats. Metabolism. 2001; 50:889-93. [PubMed: 11474475]

85. Korner J, Chua S, WIlliams J, Leibel R, Wardlaw S. Regulation of hypothalamic proopiomalanocortin by lean and obese rats. Neuroendocrinol. 1999; 70:377-83.

86. Ollmann M, Wilson B, Yang Y, Kerns J, Chen Y, Barsh G. Antagonism of central melanocortin receptors in vitro and in vivo by agouti-related protein. Science. 1997; 278:135-38. [PubMed: 9311920]

87. Farooqi I, Keogh J, Yeo G, Lank E, Ceetham T, O'Rahilly S. Clinical spectrum of obesity and mutations in the melanocortin 4 receptor gene. N Eng J Med. 2003; 348:1085-95.

88. Krude H, Biebermann H, Luck W, Horn R, Brabant G, Gruters A. Severe early-onset obesity, adrenal insufficiency, and red hair pigmentation caused by POMC nutations in humans. Nat Genet. 1998; 19:155-57. [PubMed: 9620771]

89. Yaswen L, Diehl N, Brennan M, Hochgeswender U. Obesity in the mouse model of proopiomelanocortin deficiency responds to peripheral melanocortin. Nat Med. 1999; 5:1066-70. [PubMed: 10470087]

90. Naggert JK, Fricker LD, Varlamov O, Nishin RM, Rouille T, Steiner DF, et al. Hyperproinsulinaemia in obese fat/fat mice associated with a carboxypeptidase E mutation which reduces enzyme activity. Nature Genet. 1995; 10:135-42. [PubMed: 7663508] 
91. Jackson RS, Creemers JWM, Ohagi S, Raffin-Sanson M-L, Sanders L, Montague CT, et al. Obesity and impaired prohormone processing associated with mutations in the human prohormone convertase 1 gene. Nature Genetics. 1997; 16:303. [PubMed: 9207799]

92. Korner J, Wardlaw S, Liu S, Conwell I, Leibel R, Chua S. Effects of leptin receptor mutation on Agrp gene expression in fed and fasted lean and obese (LA/N-faf) rats. Endocrinol. 2000; 141:2465-71.

93. Solinas G, Summermatter S, Mainieri D, Gubler M, Pirola L, Wymann M, et al. The direct effect of leptin on skeletal muscle thermogenesis is mediated by substrate cycling between de novo lipogenesis and lipid oxidation. Febs. 2004; 577:539-44.

94. Satoh N, Ogawa Y, Katsuura G, Numata Y, Tsuji T, Hayase M, et al. Sympathetic activation of leptin via the ventromedial hypothalamus: leptin-induced increase in catecholamine secretion. Diabetes. 1999; 48:1787-93. [PubMed: 10480609]

95. Heymsfield SB, Greenberg AS, Fujioka K, Dixon RM, Kushner R, Hunt T, et al. Recombinant leptin for weight loss in obese and lean adults: A randomized, controlled, dose-escalation trial. JAMA. 1999; 292:1568-75. [PubMed: 10546697]

96. Campfield L, Smith F, Guisez Y, Devos R, Burn P. Recombinant mouse OB protein: Evidence for a peripheral signal linking adiposity and central neural networks. Science. 1995; 269:546-48. [PubMed: 7624778]

97. Rosenbaum M, Goldsmith R, Bloomfield D, Magnano A, Weimer L, Heymsfield S, et al. Low dose leptin reverses skeletal muscle, autonomic, and neuroendocrine adaptations to maintenance of reduced weight. J Clin Invest. 2005; 115:3579-86. [PubMed: 16322796]

98. Ravussin E, Smith S, Mitchell J, Shringarpure R, Shan K, Maier H, et al. Enhanced weight loss with pramlintide/metreleptin: an integrated neurohormonal approach to obesity pharmacotherapy. Obesity. 2009; 17:1736-43. [PubMed: 19521351]

99. Welt C, Chan J, Bullen J, Murphy R, Smith P, DePaoli A, et al. Recombinant human leptin in women with hypothalamic amenorrhea. N Eng J Med. 2004; 351:987-97. 


\section{Table 1}

Changes in energy expenditure, autonomic nervous system function, and neuroendocrine function in subjects maintaining a reduced body weight with or without leptin "replacement" 1, 97, 99

\begin{tabular}{|l|l|l|}
\hline \multicolumn{2}{|c|}{ Effects of 10\% Reduced Weight Maintenance } & $\begin{array}{l}\text { Effects of Leptin Administration to Weight- } \\
\text { Reduced Subjects }\end{array}$ \\
\hline \multicolumn{3}{|c|}{ Energy Expenditure } \\
\hline Twenty-four-hour energy expenditure & Decreased (-15\%) & Reversed \\
\hline Resting energy expenditure & Decreased or unchanged & No significant change \\
\hline Thermic effect of feeding & Unchanged & Unchanged \\
\hline Non-resting energy expenditure & Decreased (-30\%) & Reversed \\
\hline Skeletal muscle work efficiency & Increased (20\%) & Reversed \\
\hline \multicolumn{3}{|c|}{ Neuroendocrine Function } \\
\hline Sympathetic Nervous System tone & Decreased (-40\%) & Reversed \\
\hline Parasympathetic Nervous System tone & Increased (80\%) & Unchanged \\
\hline & \multicolumn{3}{|c|}{ Unchanged } \\
\hline Thyroid stimulating hormone & Decreased (-18\%) & Reversed \\
\hline Triiodothyronine & Decreased (-7\%) & Reversed \\
\hline Thyroxine & Decreased (-9\%) & Reversed \\
\hline Gonadotropins & Decreased & Reversed \\
\hline Circulating Leptin & Decreased (proportional to fat mass) &
\end{tabular}


Table 2

Studies of skeletal muscle in weight reduced subjects by ergometry, ${ }^{31} \mathrm{P}-\mathrm{NMR}$ spectroscopy, and analysis of vastus lateralis muscle biopsy specimens 27,97 .

\begin{tabular}{|l|l|l|l|}
\hline & Ergometry & ${ }^{31}$ P-NMR spectroscopy & Biopsy \\
\hline Efficiency & NME $\uparrow 20 \%$ at low level exercise. & $\begin{array}{l}20 \% \uparrow(\mathrm{Pi} / \mathrm{PCr} \text { at low level exercise. } \\
18 \% \downarrow \mathrm{ATP} \text { cost/muscle contraction. }\end{array}$ & \\
\hline Fuel Utilization & $\begin{array}{l}19 \% \uparrow \text { in } \% \text { calories used derived } \\
\text { from FFA oxidation during low } \\
\text { level exercise }\end{array}$ & $\begin{array}{l}18 \% \uparrow \mathrm{Pi} \text { (FFA/glucose oxidation potential). } \\
\text { No change kPCr (oxidative potential) }\end{array}$ & $\begin{array}{l}12 \% \downarrow \text { PFK (glycolytic) activity, } \\
17 \% \downarrow \text { PFK/COX (glycolytic/FFA } \\
\text { oxidative activity) } \\
\text { No significant change in FFA } \\
\text { oxidative enzyme activities }\end{array}$ \\
\hline
\end{tabular}

Abbreviations: COX, cytochrome oxidase; kPCr, phosphocreatine recovery constant; FFA, free fatty acids; NMR, nuclear magnetic resonance; $\mathrm{PCr}$, phosphocreatine; PFK, phosphofructokinase; $\mathrm{Pi}$, inorganic phosphate 